\title{
Prediksi Harga Emas Menggunakan Univariate Convolutional
} Neural Network

\author{
Imam Halimi ${ }^{\star 1}$, Yufis Azhar ${ }^{2}$, Gita Indah Marthasari ${ }^{3}$ \\ 1,2,3Teknik Informatika/Universitas Muhammadiyah Malang \\ ihalimi80@gmail.com*1, yufis@umm.ac.id², gita@umm.ac.id ${ }^{3}$
}

\begin{abstract}
Abstrak
Dalam berinvestasi, tak lepas dengan menebak naik turunya harga agar tidak rugi dalam berinvestasi. Hal ini diperlukan dukungan teknologi untuk dapat mengetahui informasi dalam menghadapi harga yang selalu berubah-ubah setiap hari dan bahkan setiap jamnya. Investor dalam hal ini untuk komoditi emas harus dapat memprediksi harga yang selalu serubah-ubah tersebut sebelum melakukan trasnsaksi jual maupun beli, agar investor tepat dalam melakukan aktivitas jual maupun beli saham. Dengan demikian, penulis akan membuat penelitian mengenai prediksi harga emas dunia, yang bermanfaat bagi investor maupun masyarakat yang akan melakukan jual beli emas dalam bentuk saham ataupun barang agar tepat dalam mengambil keputusan. Tujuan dari prediksi adalah memperkecil kesalahan, sehingga selisih antara perkiraan dengan kejadian yang sebenarnya diminimalkan. Suatu prediksi tidak dapat dipastikan tepat sepenuhnya, tetapi memungkinkan untuk memberikan hasil yang mendekati dengan kejadian sebenarnya. Algoritma yang digunakan dalam penelitian ini adalah Convolutional Neural Network (CNN). CNN termasuk dalam bidang Deep Learning (DL), yang termasuk dalam sub bidang dari Machine Learning (ML), yang mana menerapkan konsep dasar algoritma ANN dengan lapisan yang lebih banyak. Dalam penelitian ini, penulis menggunakan pendekatan univariate CNN. Dilakukan beberapa pengujian pada parameter model CNN. Hasil terbaik ditunjukan pada model 1 yaitu pengujian dense kondisi 5, yaitu dengan parameter model filters $=64$, kernel $=2$, pooling $=2$, epochs $=2.000$, dan dense $=50$ dengan hasil RMSE yaitu 690,40.
\end{abstract}

Kata Kunci: Prediksi, Harga Emas, Convolutional Neural Network, Univaraiate, Deep Learning

\begin{abstract}
Investing activities deal with predicting the prices to avoid loss. Advanced technology is required to access various information regarding the fluctuating price everyday even every hour. In the context of this research, investors, especially investors in gold commodities should be able to predict the gold price before making transactions. Hence, investors will be able to buy or sell their stocks precisely. Regarding to those reasons, the researcher is interested in conducting research on the prediction of global gold price which results will be beneficial for investors and broader community to help them making precise decision to buy or sell gold commodities and stocks. Making precise prediction is meant to minimize the chance of making mistakes as it closes the gap between what has been expected and the outcome. Predictions cannot be guaranteed precise, yet predictions might be close to the outcome. In this research, Convolutional Neural Network (CNN) algorithm will be used. CNN belongs to the Deep Learning (DL), a sub field of Machine Learning (ML) in which basic ANN algorithm with more layers is employed. A univariate CNN approach and several tests involving CNN model parameters were administered which results showed the score for model 1 of parameter; filters $=64$, kernel $=2$, pooling $=2$, epochs $=$ 2.000 and dense $=50$ and RMSE outcome of 690,40.
\end{abstract}

Keywords: Prediction, Gold Price, Convolutional Neural Network, Univariate, Deep Learning

\section{Pendahuluan}

Emas merupakan logam yang memiliki berbagai macam bentuk dan fungsi yang berbeda. Selain untuk perhiasan, emas juga digunakan dalam keguanan berbagai macam bidang, seperti bidang industri, kedokteran, dan ekonomi, dimana penggunaanya dapat digabungkan dengan jenis logam lainnya [1]. Selain itu, emas merupakan tolak ukur ekonomi suatu negara dalam hal kekayaan negara dan sebaagi devisa negara ataupun alat pembayaran [2]. Pada tahun 2008, Indonesia mrngalami krisis moneter, di tahun tersebut masyakat dalam hal ini investor, banyak 
yang beralih untuk investasi emas dan menjual sahamnya [1]. Komoditi emas banyak digunakan investor untuk berinvestasi. Tidak seperti saham yang dapat diinvestasi secara virtual atau lembar saham saja, investasi emas dapat berupa barang yang bisa diperjual belikan secara bebas dipasaran maupun perusahaan. Dengan demikian, berinvestasi emas cenderung aman untuk dilakukan [3].

Dalam berinvestasi emas, tak lepas dengan menebak naik turunya harga agar tidak rugi dalam berinvestasi. Investor emas harus dapat memprediksi harga yang selalu serubah-ubah tersebut sebelum melakukan trasnsaksi jual maupun beli, agar investor tepat dalam melakukan aktivitas jual maupun beli saham. Dengan demikian, penulis akan membuat penelitian mengenai prediksi harga emas dunia, yang bermanfaat bagi investor maupun masyarakat yang akan melakukan jual beli emas dalam bentuk saham ataupun barang agar tepat dalam mengambil keputusan.

Jenis data yang akan digunakan dalam penelitian ini adalah jenis data time series, dimana data tersebut berurutan berdasarkan waktu yang telah terjadi (data historis). Suatu prediksi tidak dapat dipastikan tepat sepenuhnya, tetapi memungkinkan untuk memberikan hasil yang mendekati dengan kejadian sebenarnya [4]. Terdapat beberapa metode yang digunakan untuk prediksi, yaitu salah satunya yang menggunakan data time series atau data historis adalah Artificial Neural Network (ANN). ANN merupakan algoritma yang menghasilkan suatu pola atau model dari data yang ditentukan [5]. ANN termasuk dalam Machine Learning (ML), yang dapat mengoptimalkan performa sistem menggunakan data histori atau sampel data [6]. Algoritmaalgoritma dalam kecerdasan buatan telah banyak dilakukan penelitian dan pengembangan, salah satu pengembangan dari algoritma ANN, yaitu Convolutional Neural Network (CNN). CNN termasuk dalam bidang Deep Learning (DL), yang termasuk dalam sub bidang dari ML, yang mana menerapkan konsep dasar algoritma ANN dengan lapisan yang lebih banyak [5].

Terdapat beberapa penelitian dengan berbagai metode yang berbeda terkait dengan prediksi seperti dalam kasus ini, yaitu prediksi harga emas. Seperti pada penelitian sebelumnya yang berjudul "Optimasi Data Latih Menggunakan Algoritma Genetika untuk Peramalan Harga Emas Berbasis Generalized Regression Neural Network", yang menerapkan metode Generalized Regression Neural Network (GRNN) dan metode theta untuk meramalkan harga emas [7]. Selain itu, pada penelitian yang berjudul "Prediksi Harga Emas Menggunakan Metode Neural Network Backropagation Algoritma Conjugate Gradient", yang mengimplementasikan algoritma Conjugate Gradient untuk memprediksi harga emas dengan menerapkan data inputan untuk data latih [8]. Dalam penelitian yang berjudul "Prediksi Harga Emas dengan Menggunakan Metode Naïve Bayes dalam Investasi untuk Meminimalisasi Resiko", yang menerapkan metode Naïve Bayes untuk memprediksi harga logam mulia emas pegadaian [9]. Terdapat beberapa penelitian prediksi yang menngunakan data time series dengan menerapkan metode CNN. Pada penelitian yang berjudul "Convolutional Neural Networks for Energy Time Series Forecasting" menunjukkan bahwa MLP dan CNN adalah metode prediksi yang akurat pada empat data time series yang digunakan, yaitu data pada tenaga surya di Australia, Listrik di Australia, Listrik di Spanyol, dan Listrik di Portugal [10]. Sedangkan pada penelitian "Forecasting Hungarian Forint Exchange Rate with Convolutional Neural Networks" metode CNN menghasilkan prediksi yang lebih baik daripada metode Random Walk (RW), Autoregresif Integrated Moving Average (ARIMA), dan Multi-layer Perceptron (MLP) [11].

Terdapat dua pendekatan untuk prediksi data time series, yaitu univariate, yang hanya menggunakan data sebelumnya, dan multivariate, yang menggunakan informasi dari sumber yang berbeda data sebelumnya dan data lain yang berkaitan [10]. Dalam penelitian ini, penulis menggunakan pendekatan univariate. Harga emas tidak banyak dipengaruhi atau berkaitan dengan data lainnya, seperti inflasi, kurs dollar, dan suku bunga [12].

\section{Metode Penelitian \\ 2.1 Dataset}

Data primer merupakan data yang diperoleh secara langsung dari sumber data tersebut yang berhubungan dengan penelitian yang dilakukan, dalam hal ini adalah data harga emas. Pada penelitian ini data yang dikumpulan diperoleh dari website harga-emas.org. Data yang diambil adalah history harga spot emas dunia dari 1 November 2018 hingga 31 Desember 2018, dengan jumlah 2.928 record, yang digunakan sebagai acuan penelitian dalam menganalisa.

REPOSITOR, Vol. 1, No. 2, Desember 2019: 105-116 


\subsection{Penentuan Variabel}

Menurut sutau penelitian, harga emas tidak banyak dipengaruhi atau berkaitan dengan data lainnya, seperti inflasi, kurs dollar, dan suku bunga. Seperti pada penelitian yang berjudul "Pengaruh Inflasi, Kurs Dollar dan Suku Bunga Terhadap Harga Emas di Indonesia" menunjukkan bahwa variabel inflasi berpengaruh positif dan signifikan terhap harga emas hanya sebesar 3,68 $\%$. Sedangkan variable nilai tukar rupiah terhadap USD berpengaruh positif dan signifikan hanya sebesar $0,87 \%$. Dan Variabel BI rate berpengaruh negatif dan signifikan terhadap harga emas sebesar $21,8 \%$ [12]. Jadi, variabel yang digunakan dalam penelitian ini adalah Waktu sebagai Identitas (Id) dan IDR/gr sebagai label. Yang mana hanya satu jenis harga yang digunakan, yaitu IDR/gr unruk dilakukan prediksi.

\subsection{Penentuan Time Frame}

Dalam histrory harga spot emas dunia pada website harga-emas.org, terdapat 3 time frame yang berbeda yang bisa digunakan, yaitu 30 menit, 1 hari, dan 1 bulan. Penulis menggunakan time frame 30 menit, karena dalam waktu per 30 menit sudah terjadi perubahan harga yang fluktuatif.

\subsection{Preprocessing}

Data harga emas yang akan digunakan untuk penelitian disimpan dalam format tabel dalam excel (.xls), agar memudahkan dalam pengolahan data. Contoh dari data set bisa dilihat pada Tabel 1. Pada tabel tersebut merupakan data mentah yang didapat dari harga-emas.org yang belum dilakukan penanganan khusus. Atribut dalam tabel tersebut, yaitu tanggal, waktu, USD/oz, USD/gr, IDR/USD, dan IDR/gr. Dan yang akan digunakan dalam prediksi adalah IDR/gr saja dengan menggunakan tanggal dan waktu untuk pengurutan data.

Tabel 1. Data Set Harga Emas Time Frame 30 menit

\begin{tabular}{cccccc}
\hline Tanggal & Waktu & USD/oz & USD/gr & IDR/USD & IDR/gr \\
\hline 1-Nov-18 & $0: 00$ & $1.214,89$ & 39,06 & $15.227,00$ & $594.760,84$ \\
1- Nov-18 & $0: 30$ & $1.214,20$ & 39,04 & $15.227,00$ & $594.423,05$ \\
1- Nov-18 & $1: 00$ & $1.213,07$ & 39,00 & $15.227,00$ & $593.869,84$ \\
1- Nov-18 & $1: 30$ & $1.214,25$ & 39,04 & $15.227,00$ & $594.447,52$ \\
1- Nov-18 & $2: 00$ & $1.214,09$ & 39,03 & $15.227,00$ & $594.369,19$ \\
1- Nov-18 & $2: 30$ & $1.214,48$ & 39,05 & $15.227,00$ & $594.560,12$ \\
$\ldots$ & $\ldots$ & $\ldots$ & $\ldots$ & $\ldots$ & $\ldots$ \\
31-Des-18 & $23: 30$ & $1.282,07$ & 41,22 & $14.481,00$ & $596.899,69$ \\
\hline
\end{tabular}

Dalam penelitian ini, preprocessing atau preparasi ada dua tahap yang dilakukan, yaitu cleansing data dan repair data.

1) Cleansing Data: Suatu proses dimana data yang tidak diperlukan atau data yang dianggap akan menghambat proses data mining akan dihapus (Dosenpendidikan.com, 2014) dalam [13]. Tabel setelah dilakukan cleansing data akan menjadi seperti pada Tabel 2. Data yang digunakan untuk prediksi hanya atribut atau feature IDR/gr, yaitu harga spot emas dunia dalam rupiah satuan gram. Sedangkan role dari atribut tanggal dan waktu merupakan auxiliary, yaitu alat bantu atau pendukung dalam urutan harga secara time series.

2) Repair Data: Proses perbaikan struktur atau penulisan data jika ada data yang akan digunakan mengalami kesalahan penulisan yang bisa berpengaruh terhadap hasil pada proses analisis data. Data yang akan di repair adalah data yang terdapat pada atribut IDR/gr. Hal ini dilakukan karena data yang terdapat pada web sumber merupakan format penulisan angka Indonesia, yang mana formatnya tidak dikenali dalam Python. Contohnya adalah pada web sumber data set tertulis 594.760,84, angka ini terbaca String atau tipe data teks dalam Python. Maka, format penulisan diubah sesuai dengan format yang terbaca angka oleh Python, yaitu menjadi 594760.0. Proses setelah repair ditunjukkan pada Tabel 3.

\begin{tabular}{|c|c|c|}
\hline Tanggal & Waktu & IDR/gr \\
\hline 1-Nov-18 & 0:00 & $594.760,84$ \\
\hline 1-Nov-18 & $0: 30$ & $594.423,05$ \\
\hline
\end{tabular}




\begin{tabular}{ccc}
\hline 1-Nov-18 & $1: 00$ & $593.869,84$ \\
1-Nov-18 & $1: 30$ & $594.447,52$ \\
1-Nov-18 & $2: 00$ & $594.369,19$ \\
1-Nov-18 & $2: 30$ & $594.560,12$ \\
$\ldots$ & $\ldots$ & $\ldots$ \\
31-Dec-18 & $23: 30$ & $596.899,69$ \\
\hline
\end{tabular}

Tabel 3. Data Set Setelah Repair

\begin{tabular}{ccc}
\hline Tanggal & Waktu & IDR/gr \\
\hline 1-Nov-18 & $0: 00$ & 594760.84 \\
1-Nov-18 & $0: 30$ & 594.423 .05 \\
1-Nov-18 & $1: 00$ & 593869.84 \\
1-Nov-18 & $1: 30$ & 594447.52 \\
1-Nov-18 & $2: 00$ & 594369.19 \\
1-Nov-18 & $2: 30$ & 594560.12 \\
$\ldots$ & $\ldots$ & $\ldots$ \\
31-Dec-18 & $23: 30$ & 596899.69 \\
\hline
\end{tabular}

\subsection{Model Univariate CNN}

Arsitektur CNN yang digunakan ditunjukkan pada Gambar 1 dan model CNN yang digunakan dapat dilihat pada Gambar 1.

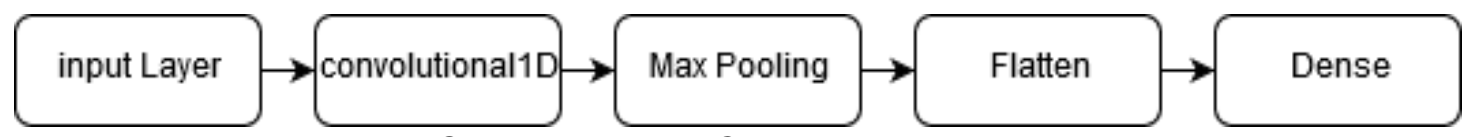

Gambar 1. Model CNN yang Digunakan

\subsection{Evaluasi Hasil}

Evaluasi hasil prediksi dalam penelitian ini menggunakan Root Mean Squared Error (RMSE). Untuk lebih memudahkan penulis dalam melakukan validasi maka perhitungan RMSE dilakukan dengan menggunakan bantuan software Microsoft Excel 2016.

\section{Hasil Penelitian dan Pembahasan}

\subsection{Model Pengujian}

Komposisi data yang digunakan dalam penelitian ini, yaitu jumlah data training $70 \%$ dan data testing $30 \%$, yaitu dengan jumlah 2.050 untuk data training dan 878 untuk data testing. Model pengujian untuk parameter model CNN yang digunakan adalah pengujian jumlah pada filters, kernel, pooling, epochs, dan dense. Optimasi dalam pengujian ini menggunakan Adam version of stochastic gradient descent dan dioptimalkan menggunakan Mean Squared Error (MSE).

a) Model 1, yaitu menggunakan 3 angka pertama data real untuk prediksi dan selanjutnya hasil prdiksi tersebut akan digunakan untuk prediksi berikutnya, dan seterusnya.

b) Model 2, yaitu keseluruhan prediksi menggunkaan data real untuk prediksi berikutnya, dan seterusnya.

\subsection{Pengujian}

\subsubsection{Pengujian Awal}

Pengujian awal dilakukan untuk mengetahui hasil prediksi awal sebelum dilakukan penanganan atau pengujian lain. Parameter model pengujian awal yang diterapkan yaitu Filters $=64$, Kernel $=2$, Pooling Size $=2$, Epochs $=1.000$, dan Dense $=50$. Setiap pengujian dilakukan percobaan eksekusi tiga kali.

\subsubsection{Model 1}

Gambar 2 merupakan hasil prediksi dan RMSE pada model 1 dan Gambar 3 merupakan grafik selisih absolute antara harga dan rata-rata hasil prediksi pada setiap data pada model 1. Dimana dapat diketahui bahwa semakin banyak atau semakin lama waktu untuk memprediksi, semakin tinggi selisih yang didapat. Secara keseluruhan, RMSE yang didapat adalah 54.946,32.

REPOSITOR, Vol. 1, No. 2, Desember 2019: 105-116 
Karena selisih yang didapatkan semakin lama semakin buruk, maka penulis mengambil beberapa data saja untuk dilakukan pengujian selanjutnya. Dari hasil pengujian yang telah dilakukan, prediksi dalam penelitian ini dengan hasil terbaik hanya didapatkan untuk prediksi 66 per 30 menit ke depan (66 × 30 menit) atau sekitar 33 jam ke depan. Penulis mengambil batas selisih dibawah 5000 .

\begin{tabular}{|c|c|c|c|c|c|c|}
\hline \multicolumn{7}{|c|}{ Pengujian Awal } \\
\hline & & & & & RMSE : & 54946.32 \\
\hline & \multicolumn{4}{|c|}{ Hasil prediksi } & RMSE (66 data) : & 2394.40 \\
\hline Harga & Percobaan 1 & Percobaan 2 & Percobaan 3 & Rata-rata & Selisih Absolute & Squared Residual \\
\hline 581716.17 & 582174.25 & 582604.90 & $581480.25^{\prime}$ & 582086.47 & 370.30 & 137119.62 \\
\hline 581921.80 & 581910.25 & 582498.25 & $581123.90^{\prime}$ & 581863.55 & 58.25 & 3393.06 \\
\hline 580215.99 & 581842.90 & 582758.60 & $580669.00^{\prime}$ & 581756.83 & 1540.84 & 2374198.18 \\
\hline 580650.62 & 581753.56 & 582846.60 & $580333.06^{\prime}$ & 581644.41 & 993.79 & 987611.94 \\
\hline 580505.75 & 581606.25 & 582998.75 & $579921.60^{\prime}$ & 581508.87 & 1003.12 & 1006243.05 \\
\hline 580818.87 & 581525.70 & 583124.44 & $579534.56^{\prime}$ & 581394.90 & 576.03 & 331810.56 \\
\hline 580716.05 & 581401.44 & 583260.10 & $579156.56^{\prime}$ & 581272.70 & 556.65 & 309859.22 \\
\hline 581136.66 & 581294.40 & 583392.06 & $578759.60^{\prime}$ & 581148.69 & 12.03 & 144.64 \\
\hline 580697.36 & 581187.60 & 583525.50 & $578378.25^{\prime}$ & 581030.45 & 333.09 & 110948.95 \\
\hline 581169.38 & 581073.75 & 583658.40 & $577990.25^{\prime}$ & 580907.47 & 261.91 & 68598.59 \\
\hline 580753.44 & 580966.94 & 583791.56 & $577602.70^{\prime}$ & 580787.07 & 33.63 & 1130.75 \\
\hline
\end{tabular}

Gambar 2. Hasil Prediksi dan RMSE Model 1

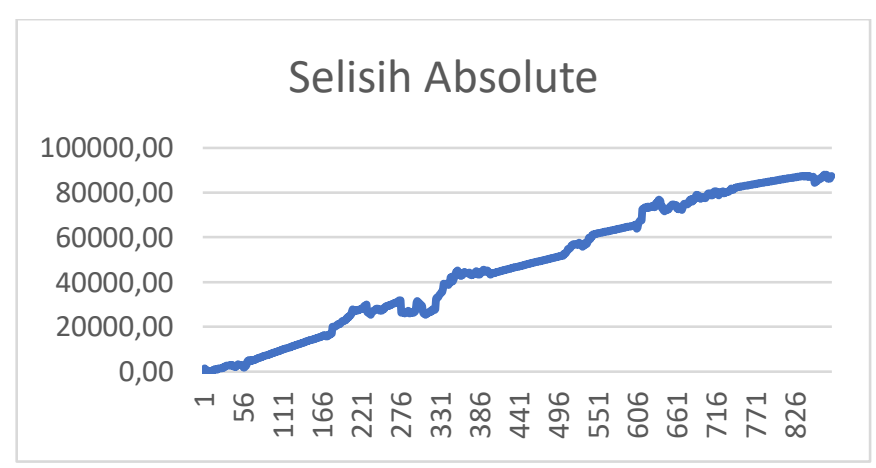

Gambar 3. Grafik Selisih Absolute Model 1

\subsubsection{Model 2}

Gambar 4 merupakan hasil prediksi dan RMSE pada model 2 dan Gambar 5 merupakan grafik selisih absolute antara harga dan rata-rata hasil prediksi pada setiap data pada model 1. Dari gambar tersebut dapat diketahui bahwa selisih absolute yang didapatkan jauh lebih baik dari model 1. Secara keseluruhan, RMSE yang didapat adalah 716.07. Karena selisih yang didapatkan keseluruhan cenderung stabil, atau nilainya tidak berbeda jauh, maka penulis mengambil keselurihan data untuk dilakukan pengujian selanjutnya.

\begin{tabular}{|r|r|r|r|r|r|r|}
\hline & \multicolumn{9}{|c|}{ Pengujian Awal } \\
\cline { 3 - 7 } & & & & RMSE : & \\
\hline Harga & Percobaan 1 & Percobaan 2 & Percobaan 3 & Rata-rata & Selisih Absolute & Squared Residual \\
\hline 581716.17 & 582646.00 & 581396.60 & 582531.56 & 582191.39 & 475.22 & 225830.88 \\
\hline 581921.80 & 582288.56 & 580977.00 & 582219.44 & 581828.33 & 93.47 & 8736.02 \\
\hline 580215.99 & 582065.60 & 580837.25 & 581940.56 & 581614.47 & 1398.48 & 1955746.31 \\
\hline 580650.62 & 582071.90 & 580861.80 & 581970.20 & 581634.63 & 984.01 & 968282.24 \\
\hline 580505.75 & 581228.80 & 579910.40 & 581307.75 & 580815.65 & 309.90 & 96038.01 \\
\hline 580818.87 & 580817.10 & 579588.94 & 580732.25 & 580379.43 & 439.44 & 193107.51 \\
\hline 580716.05 & 580920.75 & 579710.44 & 580796.50 & 580475.90 & 240.15 & 57673.62 \\
\hline 581136.66 & 581002.94 & 579766.70 & 580907.40 & 580559.01 & 577.65 & 333675.67 \\
\hline 580697.36 & 581190.90 & 579992.50 & 581059.50 & 580747.63 & 50.27 & 2527.41 \\
\hline 581169.38 & 581221.06 & 580034.75 & 581128.60 & 580794.80 & 374.58 & 140307.68 \\
\hline 580753.44 & 581232.94 & 580053.70 & 581138.40 & 580808.35 & 54.91 & 3014.74 \\
\hline
\end{tabular}

Gambar 4. Hasil Prediksi dan RMSE model 2 


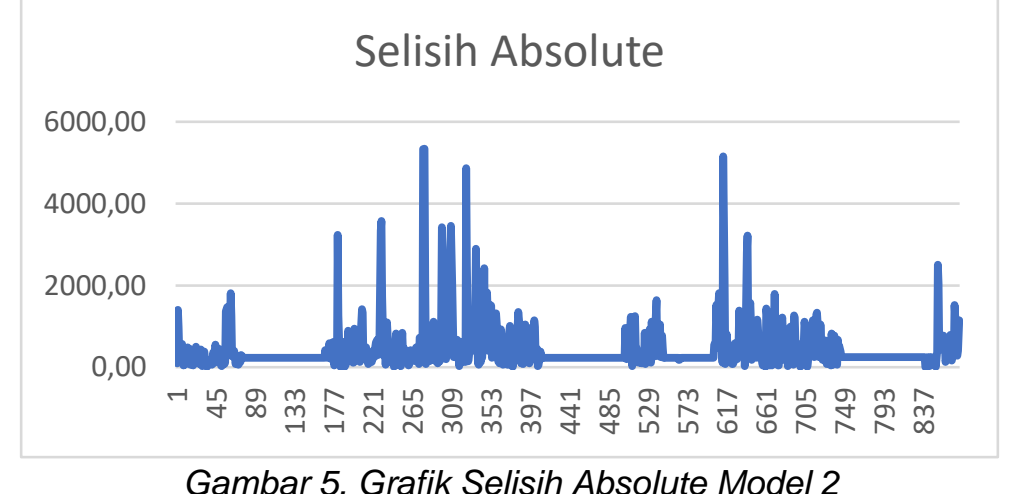

\subsubsection{Pengujian Filters}

Gambar 5. Grafik Selisih Absolute Model 2

Pengujian filters dilakukan 10 kondisi dengan masing-masing kondisi dilakukan tiga kali percobaan atau eksekusi program. Parameter pengujian filter model 1 dan model 2 dapat dilihat pada Tabel 4, dan hasil pengujian filters model 1 dan model 2 dapat dilihat pada Tabel 5. Dari tabel tersebut dapat diketahui bahwa pengujian filter terbaik, yaitu model 1 pada kondisi 3 dengan RMSE 1.829,24, Dan model 2 pada kondisi 7 dengan RMSE 696,11.

Tabel 4. Parameter Pengujian Filters Model 1 dan Model 2

\begin{tabular}{cccccc}
\hline \multirow{2}{*}{ Kondisi } & \multicolumn{5}{c}{ Parameter Pengujian } \\
\cline { 2 - 6 } & Filters & Kernel Size & Pooling Size & Epochs & Dense \\
\hline Kondisi 1 & 1 & 2 & 2 & 1.000 & 50 \\
Kondisi 2 & 2 & 2 & 2 & 1.000 & 50 \\
Kondisi 3 & 4 & 2 & 2 & 1.000 & 50 \\
Kondisi 4 & 8 & 2 & 2 & 1.000 & 50 \\
Kondisi 5 & 16 & 2 & 2 & 1.000 & 50 \\
Kondisi 6 & 32 & 2 & 2 & 1.000 & 50 \\
Kondisi 7 & 64 & 2 & 2 & 1.000 & 50 \\
Kondisi 8 & 128 & 2 & 2 & 1.000 & 50 \\
Kondisi 9 & 256 & 2 & 2 & 1.000 & 50 \\
Kondisi 10 & 512 & 2 & 2 & 1.000 & 50 \\
\hline
\end{tabular}

Tabel 5. Hasil Pengujian Filters Model 1 dan Model 2

\begin{tabular}{ccc}
\hline \multirow{2}{*}{ Kondisi } & \multicolumn{2}{c}{ RMSE } \\
\cline { 2 - 3 } & Model 1 & Model 2 \\
\hline Kondisi 1 & $9.971,89$ & 796,08 \\
Kondisi 2 & $4.877,92$ & 785,75 \\
Kondisi 3 & $1.829,24$ & 836,10 \\
Kondisi 4 & $4.346,78$ & 703,24 \\
Kondisi 5 & $8.913,83$ & 759,89 \\
Kondisi 6 & $8.228,83$ & 734,97 \\
Kondisi 7 & $4.991,59$ & 696,11 \\
Kondisi 8 & $7.627,43$ & 729,07 \\
Kondisi 9 & $4.073,32$ & 850.81 \\
Kondisi 10 & $11.718,86$ & 701,37 \\
\hline
\end{tabular}

\subsubsection{Pengujian Kernel}

Pengujian kernel dilakukan 2 kondisi, erdasarkan pengujian filters yang dilakukan sebelumnya, penulis menentukan model 1 pada setiap kondisi menggunakan filters $=4$, dan pada model 2 pada setiap kondisi menggunakan filters $=64$, karena RMSE yang dihasilkan memiliki hasil terbaik dari kondisi filters lainnya. Parameter pengujian kernel model 1 dapat dilihat pada Tabel 6, dan model 2 dapat dilihat pada Tabel 7, serta hasil pengujian kernel model 1 dan model 2 dapat dilihat pada Tabel 8. Dari tabel tersebut dapat diketahui bahwa pengujian kernel terbaik, yaitu model 1 pada kondisi 1 dengan RMSE 984.55, Dan model 2 pada kondisi 2 dengan RMSE 693,83 . 


\begin{tabular}{cccccc}
\multicolumn{5}{c}{ Tabel 6. Parameter Pengujian Kernel Model 1 } \\
\hline \multirow{2}{*}{ Kondisi } & \multicolumn{5}{c}{ Parameter Pengujian } \\
\cline { 2 - 6 } & Filters & Kernel Size & Pooling Size & Epochs & Dense \\
\hline Kondisi 1 & 4 & 1 & 2 & 1.000 & 50 \\
Kondisi 2 & 4 & 2 & 2 & 1.000 & 50 \\
\hline
\end{tabular}

Tabel 7. Parameter Pengujian Kernel Model 2

\begin{tabular}{cccccc}
\hline \multirow{2}{*}{ Kondisi } & \multicolumn{5}{c}{ Parameter Pengujian } \\
\cline { 2 - 6 } & Filters & Kernel Size & Pooling Size & Epochs & Dense \\
\hline Kondisi 1 & 64 & 1 & 2 & 1.000 & 50 \\
Kondisi 2 & 64 & 2 & 2 & 1.000 & 50 \\
\hline
\end{tabular}

Tabel 8. Hasil Pengujian Kernel Model 1 dan Model 2

\begin{tabular}{ccc}
\hline \multirow{2}{*}{ Kondisi } & \multicolumn{2}{c}{ RMSE } \\
\cline { 2 - 3 } & Model 1 & Model 2 \\
\hline Kondisi 1 & 984.55 & 903,33 \\
Kondisi 2 & $4.719,46$ & 693,83 \\
\hline
\end{tabular}

\subsubsection{Pengujian Pooling}

Pengujian pooling dilakukan 2 kondisi dengan masing-masing kondisi dilakukan tiga kali percobaan atau eksekusi program. Berdasarkan pengujian kernel yang dilakukan sebelumnya, penulis menentukan model 1 pada setiap kondisi menggunakan kernel $=1$, dan model 2 pada setiap kondisi menggunakan kernel $=2$, karena RMSE yang dihasilkan memiliki hasil terbaik dari kondisi kernel lainnya. Parameter pengujian pooling model 1 dapat dilihat pada Tabel 9, dan model 2 dapat dilihat pada Tabel 10, serta hasil pengujian pooling model 1 dan model 2 dapat dilihat pada Tabel 11. Dari tabel tersebut dapat diketahui bahwa pengujian pooling terbaik, yaitu model 1 pada kondisi 2 dengan RMSE 2.671,47, dan model 2 pada kondisi 2 dengan RMSE 695,78 .

Tabel 9. Parameter Pengujian Pooling Model 1

\begin{tabular}{cccccc}
\hline \multirow{2}{*}{ Kondisi } & \multicolumn{5}{c}{ Parameter Pengujian } \\
\cline { 2 - 6 } & Filters & Kernel Size & Pooling Size & Epochs & Dense \\
\hline Kondisi 1 & 4 & 1 & 1 & 1.000 & 50 \\
Kondisi 2 & 4 & 1 & 2 & 1.000 & 50 \\
\hline
\end{tabular}

Tabel 10. Parameter Pengujian Pooling Model 2

\begin{tabular}{cccccc}
\hline \multirow{2}{*}{ Kondisi } & \multicolumn{5}{c}{ Parameter Pengujian } \\
\cline { 2 - 6 } & Filters & Kernel Size & Pooling Size & Epochs & Dense \\
\hline Kondisi 1 & 64 & 2 & 1 & 1.000 & 50 \\
Kondisi 2 & 64 & 2 & 2 & 1.000 & 50 \\
\hline
\end{tabular}

Tabel 11. Hasil Pengujian Pooling Model 1 dan Model 2

\begin{tabular}{ccc}
\hline \multirow{2}{*}{ Kondisi } & \multicolumn{2}{c}{ RMSE } \\
\cline { 2 - 3 } & Model 1 & Model 2 \\
\hline Kondisi 1 & $13.944,12$ & 770.53 \\
Kondisi 2 & $2.671,47$ & 695,78 \\
\hline
\end{tabular}

\subsubsection{Pengujian Epochs}

Pengujian epochs dilakukan 10 kondisi dengan masing-masing kondisi dilakukan dua kali percobaan atau eksekusi program. Berdasarkan pengujian pooling yang dilakukan sebelumnya, penulis menentukan model 1 pada setiap kondisi menggunakan pooling $=2$, dan model 2 menggunakan pooling $=2$, karena RMSE yang dihasilkan memiliki hasil terbaik dari kondisi pooling lainnya. Parameter pengujian epoch model 1 dapat dilihat pada Tabel 12, dan model 2 dapat dilihat pada Tabel 13, serta hasil pengujian epochs model 1 dan model 2 dapat dilihat pada Tabel 14. Dari tabel tersebut dapat diketahui bahwa pengujian epochs terbaik, yaitu model 1 pada kondisi 8 dengan RMSE 726,24, dan model 2 pada kondisi 2 dengan RMSE 701,21. 
Tabel 12. Parameter Pengujian Epochs Model 1

\begin{tabular}{cccccc}
\hline \multirow{2}{*}{ Kondisi } & \multicolumn{5}{c}{ Model Pengujian } \\
\cline { 2 - 6 } & Filters & Kernel Size & Pooling Size & Epochs & Dense \\
\hline Kondisi 1 & 4 & 1 & 2 & 1.000 & 50 \\
Kondisi 2 & 4 & 1 & 2 & 2.000 & 50 \\
Kondisi 3 & 4 & 1 & 2 & 3.000 & 50 \\
Kondisi 4 & 4 & 1 & 2 & 4.000 & 50 \\
Kondisi 5 & 4 & 1 & 2 & 5.000 & 50 \\
Kondisi 6 & 4 & 1 & 2 & 6.000 & 50 \\
Kondisi 7 & 4 & 1 & 2 & 7.000 & 50 \\
Kondisi 8 & 4 & 1 & 2 & 8.000 & 50 \\
Kondisi 9 & 4 & 1 & 2 & 9.000 & 50 \\
Kondisi 10 & 4 & 1 & 2 & 10.000 & 50 \\
\hline
\end{tabular}

Tabel 13. Parameter Pengujian Epochs Model 2

\begin{tabular}{cccccc}
\hline \multirow{2}{*}{ Kondisi } & \multicolumn{5}{c}{ Model Pengujian } \\
\cline { 2 - 6 } & Filters & Kernel Size & Pooling Size & Epochs & Dense \\
\hline Kondisi 1 & 64 & 2 & 2 & 1.000 & 50 \\
Kondisi 2 & 64 & 2 & 2 & 2.000 & 50 \\
Kondisi 3 & 64 & 2 & 2 & 3.000 & 50 \\
Kondisi 4 & 64 & 2 & 2 & 4.000 & 50 \\
Kondisi 5 & 64 & 2 & 2 & 5.000 & 50 \\
Kondisi 6 & 64 & 2 & 2 & 6.000 & 50 \\
Kondisi 7 & 64 & 2 & 2 & 7.000 & 50 \\
Kondisi 8 & 64 & 2 & 2 & 8.000 & 50 \\
Kondisi 9 & 64 & 2 & 2 & 9.000 & 50 \\
Kondisi 10 & 64 & 2 & 2 & 10.000 & 50 \\
\hline
\end{tabular}

Tabel 14. Hasil Pengujian Epochs Model 1 dan Model 2

\begin{tabular}{ccc}
\hline \multirow{2}{*}{ Kondisi } & \multicolumn{2}{c}{ RMSE } \\
\cline { 2 - 3 } & Model 1 & Model 2 \\
\hline Kondisi 1 & $5.042,35$ & 701,47 \\
Kondisi 2 & 735,34 & 701,21 \\
Kondisi 3 & $1.747,57$ & 793.98 \\
Kondisi 4 & $3.408,50$ & 776,89 \\
Kondisi 5 & $10.899,91$ & 763.26 \\
Kondisi 6 & $3.351,70$ & 734,14 \\
Kondisi 7 & $11.739,96$ & 793,71 \\
Kondisi 8 & 726,24 & 710,67 \\
Kondisi 9 & 949,27 & 801,87 \\
Kondisi 10 & $9.089,29$ & 834,99 \\
\hline
\end{tabular}

\subsubsection{Pengujian Dense}

Pengujian dense dilakukan 10 kondisi dengan masing-masing kondisi dilakukan tiga kali percobaan atau eksekusi program. Berdasarkan pengujian epochs yang dilakukan sebelumnya, penulis menentukan model 1 pada setiap kondisi menggunakan epochs $=8.000$, dan model 2 menggunakan epochs $=2.000$, karena RMSE yang dihasilkan memiliki hasil terbaik dari kondisi lainnya.

Parameter pengujian dense model 1 dapat dilihat pada Tabel 15, dan model 2 dapat dilihat pada Tabel 16, serta hasil pengujian dense model 1 dan model 2 dapat dilihat pada Tabel 17. Dari tabel tersebut dapat diketahui bahwa pengujian dense terbaik, yaitu model 1 pada kondisi 5 dengan RMSE 910,67, dan model 2 pada kondisi 5 dengan RMSE 690,40.

Tabel 15. Parameter Pengujian Dense Model 1

\begin{tabular}{cccccc}
\hline \multirow{2}{*}{ Kondisi } & \multicolumn{5}{c}{ Parameter Pengujian } \\
\cline { 2 - 6 } & Filters & Kernel Size & Pooling Size & Epochs & Dense \\
\hline Kondisi 1 & 4 & 1 & 2 & 8.000 & 10
\end{tabular}

REPOSITOR, Vol. 1, No. 2, Desember 2019: 105-116 


\begin{tabular}{cccccc} 
Kondisi 2 & 4 & 1 & 2 & 8.000 & 20 \\
Kondisi 3 & 4 & 1 & 2 & 8.000 & 30 \\
Kondisi 4 & 4 & 1 & 2 & 8.000 & 40 \\
Kondisi 5 & 4 & 1 & 2 & 8.000 & 50 \\
Kondisi 6 & 4 & 1 & 2 & 8.000 & 60 \\
Kondisi 7 & 4 & 1 & 2 & 8.000 & 70 \\
Kondisi 8 & 4 & 1 & 2 & 8.000 & 80 \\
Kondisi 9 & 4 & 1 & 2 & 8.000 & 90 \\
Kondisi 10 & 4 & 1 & 2 & 8.000 & 100 \\
\hline
\end{tabular}

Tabel 16. Parameter Pengujian Dense Model 2

\begin{tabular}{cccccc}
\hline \multirow{2}{*}{ Kondisi } & \multicolumn{5}{c}{ Parameter Pengujian } \\
\cline { 2 - 6 } & Filters & Kernel Size & Pooling Size & Epochs & Dense \\
\hline Kondisi 1 & 64 & 2 & 2 & 2.000 & 10 \\
Kondisi 2 & 64 & 2 & 2 & 2.000 & 20 \\
Kondisi 3 & 64 & 2 & 2 & 2.000 & 30 \\
Kondisi 4 & 64 & 2 & 2 & 2.000 & 40 \\
Kondisi 5 & 64 & 2 & 2 & 2.000 & 50 \\
Kondisi 6 & 64 & 2 & 2 & 2.000 & 60 \\
Kondisi 7 & 64 & 2 & 2 & 2.000 & 70 \\
Kondisi 8 & 64 & 2 & 2 & 2.000 & 80 \\
Kondisi 9 & 64 & 2 & 2 & 2.000 & 90 \\
Kondisi 10 & 64 & 2 & 2 & 2.000 & 100 \\
\hline
\end{tabular}

Tabel 17. Hasil Pengujian Dense Model 1 dan Model 2

\begin{tabular}{ccc}
\hline \multirow{2}{*}{ Kondisi } & \multicolumn{2}{c}{ RMSE } \\
\cline { 2 - 3 } & Model 1 & Model 2 \\
\hline Kondisi 1 & $1.715,53$ & 705,26 \\
Kondisi 2 & $2.887,45$ & 696,28 \\
Kondisi 3 & $7.302,02$ & 718,88 \\
Kondisi 4 & 917,73 & 770,78 \\
Kondisi 5 & 910,67 & 690,40 \\
Kondisi 6 & $1.818,39$ & 882,23 \\
Kondisi 7 & $1.736,50$ & 933,45 \\
Kondisi 8 & $2.335,71$ & 698,65 \\
Kondisi 9 & $1.563,86$ & 700.65 \\
Kondisi 10 & $1.550,48$ & 863.96 \\
\hline
\end{tabular}

\subsection{Perbandingan Hasil Pengujian}

Grafik perbandingan hasil pengujian model 1 yang telah dilakukan dapat dilihat pada Gambar 6, dan perbandingan hasil pengujian model 2 dapat dilihat pada Gambar 7. Dari setiap pengujian model 1 , hasil terbaik ditunjukkan pada kondisi 3 untuk pengujian filters dengan nilai $1.829,24$, kondisi 1 untuk pengujian kerne/ dengan nilai 984.55 , kondisi 2 untuk pengujian pooling dengan nilai 2.671,47, kondisi 8 untuk pengujian epochs dengan nilai 726,24, dan kondis 5 untuk pengujian dense dengan nilai 910,67. Dapat diketahui bahwa hasil terbaik pada model 1 ditunjukan pada pengujian epochs pada kondisi 8 , yaitu dengan parameter model filters $=4$, kernel $=1$, pooling $=2$, epochs $=8.000$, dan dense $=50$ dengan hasil RMSE yaitu 726,24.

Sedangkan dari setiap pengujian model 2 pada Gambar 8, hasil terbaik ditunjukkan pada kondisi 7 untuk pengujian filters dengan nilai 966.11, kondisi 2 untuk pengujian kernel dengan nilai 693,83, kondisi 2 untuk pengujian pooling dengan nilai 695,78, kondisi 2 untuk pengujian epochs dengan nilai 701,21, dan kondis 5 untuk pengujian dense dengan nilai 690,40. Dapat diketahui bahwa hasil terbaik pada model 2 ditunjukan pada pengujian dense pada kondisi 5 , yaitu dengan parameter model filters $=64$, kernel $=2$, pooling $=2$, epochs $=2.000$, dan dense $=$ 50 dengan hasil RMSE yaitu 690,40.

Dari pengujian tersebut juga dapat diketahui beberapa perbedaan hasil RMSE pada parameter yang sama pada model 1. Seperti pada pengujian filters kondisi 3 dengan pengujian kerne/ kondisi 2, dengan parameter yang sama memiliki hasil yang berbeda yaitu 1.829,24 untuk pengujian filters dan 4.719,46 untuk pengujian kernel. Kenudian antara pengujian kernel kondisi 
1 dengan nilai 984.55 dan pengujian pooling kondisi 2 dengan nilai 2.671,47. Antara pengujian pooling kondisi 3 dengan nilai 5.183,61 dan pengujian epochs kondisi 1 dengan nilai 5.042,35. Dan antara pengujian epochs kondisi 8 dengan nilai 726,24 dan pengujian dense kondisi 5 dengan nilai 910,67.

Sedangkan pada pengujian model 2, seperti pada pengujian awal, pengujian filters kondisi 5, pengujian kernel kondisi 2, pengujian pooling kondisi 2, dan pengujian epochs kondisi 1, dengan parameter yang sama memiliki hasil yang berbeda yaitu 716.07 untuk pengujian awal, 759,89 untuk pengujian filters, 693,83 untuk pengujian kernel, 695,78 untuk pengujian pooling, dan 701,47 untuk pengujian epochs. Kenudian antara pengujian epochs kondisi 2 dengan nilai 701,21 dan pengujian dense kondisi 5 dengan nilai 690,40.

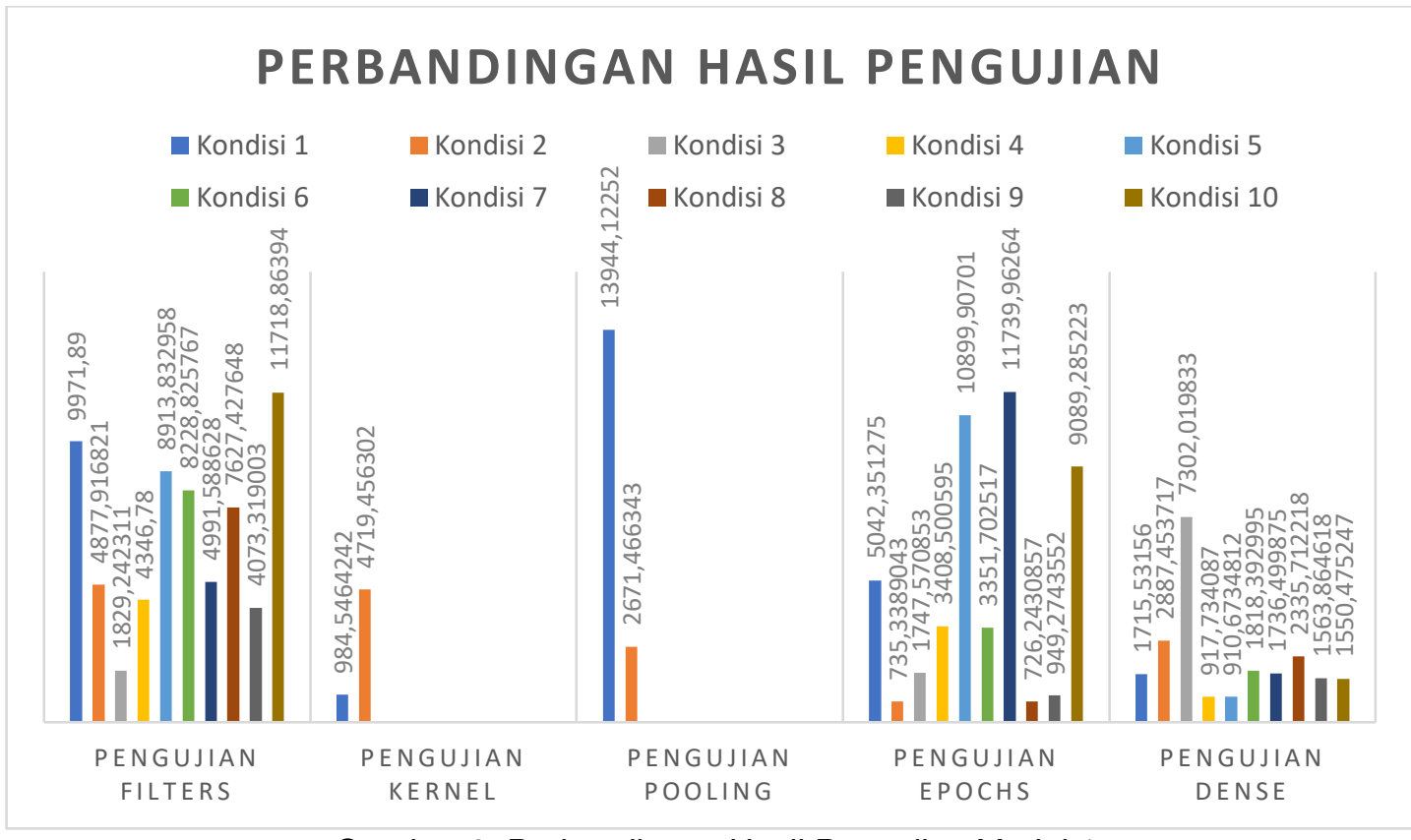

Gambar 6. Perbandingan Hasil Pengujian Model 1

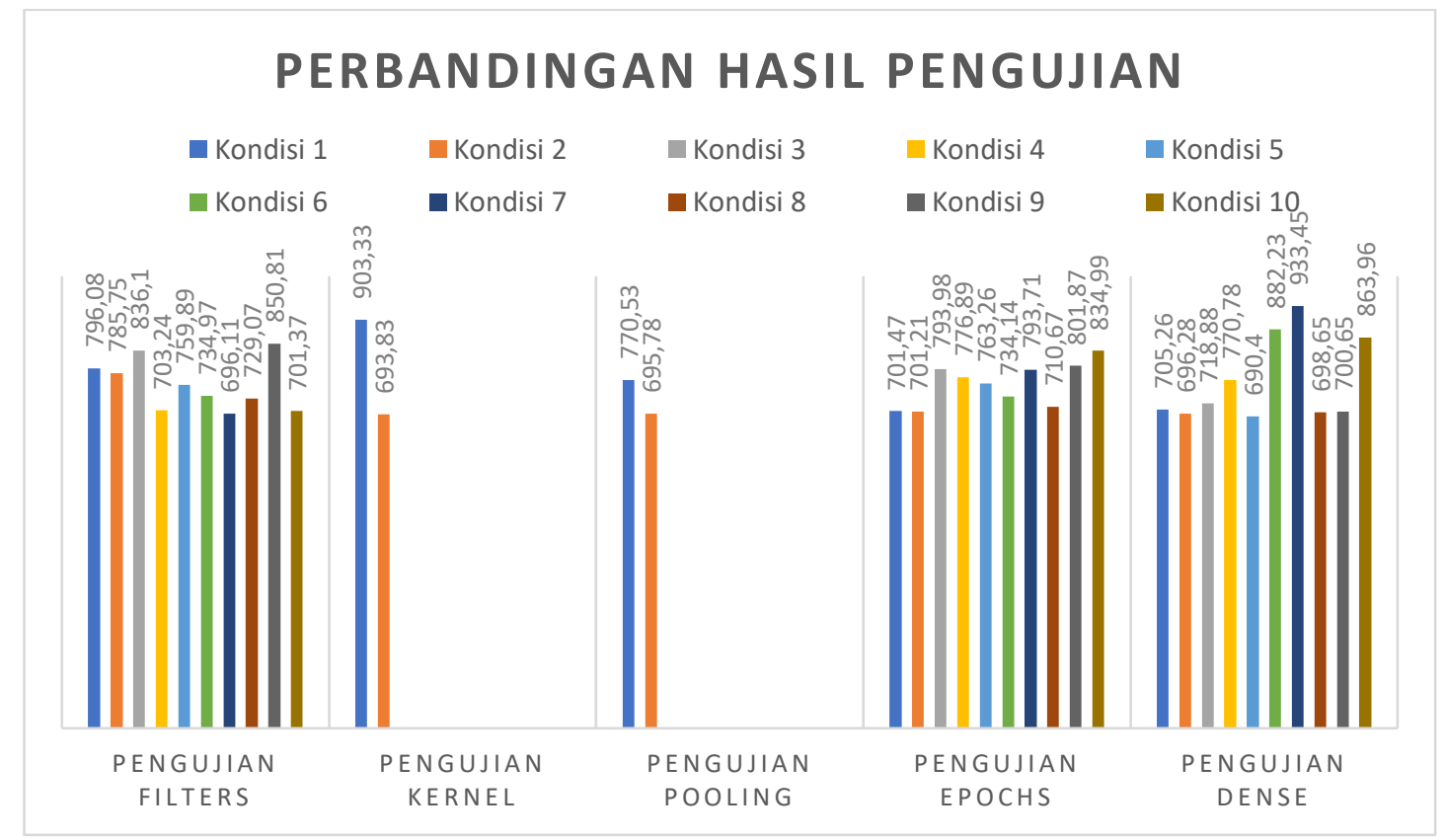

Gambar 7. Perbandingan Hasil Pengujian Model 2 


\section{Kesimpulan}

Univariate Convolutional Neural Network (CNN) dapat digunakan untuk memprediksi data time series, dalam kasus ini, yaitu harga emas. Univariate CNN untuk memprediksi menggunakan data hasil prediksi, cocok digunakan untuk memprediksi beberapa nilai kedepan saja. Hal ini didasarkan dari hasil RMSE untuk pengujian awal, yaitu 47.336,29. Univariate CNN untuk memprediksi menggunakan data asli untuk memprediksi nilai tunggal, memiliki hasil yang lebih baik dibandingkan dengan data hasil prediksi untuk prediksi berikutnya. Hasil yang didapatkan pada setiap percobaan eksekusi program dan pengujian pada setiap kondisi memiliki hasil yang selalu berubah-ubah. Hasil prediksi terbaik untuk univariate CNN menggunakan data hasil prediksi yaitu 726,24 . Hasil prediksi terbaik untuk univariate CNN menggunaka data asli yaitu 690,40 .

Untuk mendapatkan hasil yang baik, diperlukan optimasi yang tepat dari model univariate CNN, misalnya Multi-Step CNN Models dan Vector Output Model yang memungkinkan prediksi beberapa step ke depan. Ada beberapa model yang dapat digunakan untuk pengembangan pada multivariate time series, misalnya Multiple Input Series dan Multiple Parallel Series. Atau dapat menggunakan model lain seperti Multivariate Multi-Step CNN dengan optimasi Models Multiple Input Multi-Step Output dan Multiple Parallel Input and Multi-Step Output.

\section{Referensi}

[1] Yesika, "Prosedur Investasi Emas Berjangka Studi kasus pada PT. Mahadana Asta Berjangka," Sekolah Tinggi Ilmu Ekonomi Kesatuan Bogor, 2014.

[2] Y. Mahena, M. Rusli, and E. Winarso, "Prediksi Harga Emas Dunia Sebagai Pendukung Keputusan Investasi Saham Emas Menggunakan Teknik Data Mining," Kalbiscentia J. Sains dan Teknol., vol. 2, no. 1, pp. 36-51, 2015.

[3] T. B. Butar, "Pengaruh Harga Emas, Nilai Tukar Dollar (USD) dan Indeks Dow Jones Terhadap Indeks Harga Saham Gabungan (IHSG) Pada Bursa Efek Indonesia," Universitas Sumatra Utara, 2017.

[4] Herdianto, "Prediksi Kerusakan Motor Induksi Menggunakan Metode Jaringan Saraf Tiruan Backpropagation," Universitas Sumatra Utara, 2013.

[5] T. Nurhikmat, "Implementasi Deep Learning Untuk Image Classification Menggunakan Algoritma Convolutional Neural Network (CNN) Pada Citra Wayang Golek," Universitas Islam Indonesia, 2018.

[6] E. Alpaydin, Introduction to Machine Learning Second Edition. Cambridge, 2010.

[7] G. I. Marthasari and A. Djunaidy, "Optimasi Data Latih Menggunakan Algoritma Genetika untuk Peramalan Harga Emas Berbasis Generalized Regression Neural Network," J. Sist. Inf., vol. 5, no. 1, pp. 62-69, 2014.

[8] Y. Sari, "Prediksi Harga Emas Menggunakan Metode Neural Network Backropagation Algoritma Conjugate Gradient," vol. 1, no. 2, pp. 64-70, 2017.

[9] M. Guntur, J. Santony, and Yuhandri, "Prediksi Harga Emas dengan Menggunakan Metode Naïve Bayes dalam Investasi untuk Meminimalisasi Resiko," Rekayasa Sist. dan Teknol. Inf., vol. 2, no. 1, pp. 354-360, 2018.

[10] I. Koprinska, D. Wu, and Z. Wang, "Convolutional Neural Networks for Energy Time Series Forecasting," Int. Jt. Conf. Neural Networks, 2018.

[11] S. Galeshchuk and Y. Demazeau, "Forecasting Hungarian Forint Exchange Rate with Convolutional Neural Networks," Int. Conf. Behav. Econ. Socio-cultural Comput., 2017.

[12] M. Y. Wicaksono, "Pengaruh Inflasi, Kurs Dollar dan Suku Bunga Terhadap Harga Emas di Indonesia," J. Pendidik. dan Ekon., vol. 5, no. 2, pp. 143-149, 2016.

[13] C. A. Sugianto and F. Fachruddin, "Prediksi Pergerakan Harga Valas Menggunakan Algoritma Neural Network," vol. 03, no. 01, pp. 20-25, 2018. 
REPOSITOR, Vol. 1, No. 2, Desember 2019: 105-116 